\title{
COMMUNITY STRUCTURE AND POTENTIAL NITROGEN METABOLISMS OF SUBTROPICAL AQUACULTURE POND MICROBIOTA
}

\author{
NI, J. J. ${ }^{1,2,3,4, *, \#}-$ LI, X. J. ${ }^{1,2 \#}-$ CHEN, F. $^{5}-$ WU, H. H. ${ }^{6}-$ XU, M. Y. ${ }^{1,2, *}$ \\ ${ }^{1}$ Guangdong Provincial Key Laboratory of Microbial Culture Collection and Application \\ Guangdong Institute of Microbiology, Guangzhou 510070, China \\ ${ }^{2}$ State Key Laboratory of Applied Microbiology Southern China, Guangzhou 510070, China \\ ${ }^{3}$ Department of Hepatobiliary Surgery II, Guangdong Provincial Research Center of Artificial \\ Organ and Tissue Engineering, Zhujiang Hospital of Southern Medical University \\ Ghuangzhou 510280, China \\ ${ }^{4}$ State Key Laboratory of Organ Failure Research, Southern Medical University \\ Guangzhou 510515, China \\ ${ }^{5}$ Yuanjiang Bureau of Aquatic Products, Yuanjiang 413100, China \\ ${ }^{6}$ Animal Science and Technology College, Hunan Agricultural University \\ Changsha 410128, China \\ *Corresponding authors \\ M.Xu-e-mail: xumy@gdim.cn; phone: +86-020-87683656; fax: +86-020-87684471 \\ J.Ni-phone: +86-020-62783685; e-mail:nijiajia2005@126.com \\ ${ }^{\#}$ These authors contributed equally to this work.
}

(Received $25^{\text {th }}$ Jul 2018; accepted $15^{\text {th }}$ Oct 2018)

\begin{abstract}
Microorganisms play a substantial role in the aquatic nitrogen cycle. However, the community structures and metabolic potential of microbiota inhabiting subtropical aquaculture ponds are still poorly understood. In the present study, we investigated the community structure of pond microbiota by amplicons sequencing using the MiSeq sequencing platform and predicted their potential metabolic characteristics. A total of 614 dominant operational taxonomic units (OTUs) were detected from 27 samples, of which 61 were dominant in more than half of the samples. Many of the taxa observed in this study have known roles in nitrification and denitrification. In addition, most genes related to nitrogen metabolism were detected using a predictive metagenome approach, and a complementary pattern in which ponds had different genes in the same metabolic pathway emerged. These results provide basic information for the management of microbiota to control the nitrogen balance in pond water.
\end{abstract}

Keywords: culture pollution; high-throughput sequencing; metagenome; freshwater microbiota composition; nitrogen transformations

Abbreviations: ammonia nitrogen $\left(\mathrm{NH}_{4}{ }^{+}-\mathrm{N}\right)$; chemical oxygen demand (COD); constrained correspondence analysis (CCA); dissolved oxygen (DO); multivariate analysis of variance (MANOVA); operational taxonomic units (OTUs); oxidation reduction potential (ORP); pond size (PS); pond depth $(\mathrm{PD})$; principal coordinate analysis $(\mathrm{PCoA})$; total nitrogen $(\mathrm{TN})$; total phosphorus $(\mathrm{TP})$; water temperature (WT) 


\section{Introduction}

Pollution and overfishing are degrading freshwater fisheries, resulting in a huge shortage of fish products. To meet the demand for fish and fish products, the production of aquacultured freshwater fish has increased steeply (Naylor et al., 2000; FAO, 2014). Pond culture is the major aquaculture method in Asia. In China alone, there are 2,566,900 ha freshwater aquaculture ponds (Lu et al., 2015). However, this has led to serious environmental pollution (Lu et al., 2015; Liu and Diamond, 2005; Crab et al., 2007). Fish use proteins for energy production; their protein requirement is approximately two to three times higher than that of mammals. However, approximately 75\% of feed nitrogen is unutilized and remains as waste in the water (Piedrahita, 2003; Gutierrez-Wing and Malone, 2006). Accordingly, aquaculture water contains high nitrogen residues (Crab et al., 2007).

Bacteria in the water and sediments remove these nitrogen products by nitrification and denitrification (Lu et al., 2015). For instance, chemoautotrophic bacteria, such as Nitrosomonas and Nitrobacter, oxidize ammonia $\left(\mathrm{NH}_{4}{ }^{+}\right)$to nitrite $\left(\mathrm{NO}_{2}^{-}\right)$and nitrate $\left(\mathrm{NO}_{3}{ }^{-}\right)$ions, which are then removed by aquatic plants, algae, and bacteria by assimilation as a source of nitrogen (Mook et al., 2012; Shen et al., 2016). However, in stagnant water ponds, the formation of nitrogen gas is negligible and total ammonium nitrogen tends to accumulate owing to insufficient nitrification activity (Crab et al., 2007), despite anaerobic ammonium oxidation (anammox) activity in freshwater aquaculture systems (Shen et al., 2016). The accumulation of total ammonium nitrogen is toxic to fish and its discharge in pond water causes environmental pollution (Camargo et al., 2005). These results implied that bacteria play important roles in nitrogen cycle in pond water. Therefore, enumerating the microbial composition and functional genes, and their influence factors in the pond water would provide important reference information to develop novel technique measures to maintain the nitrogen balance and reduce ammonia accumulation.

To enumerate the microbial composition and describe their potential nitrogen metabolism in aquaculture ponds, in the present study, we investigated the microbial composition and nitrogen metabolic genes in subtropical aquaculture ponds of China, as well as assessed their influence factors in the pond water. The results of the present study would provide important reference information to develop novel technique measures to maintain the nitrogen balance and reduce ammonia accumulation, which would decrease the pollution pressure of pond water to natural water and reduce toxic action of ammonia to cultured fish.

\section{Materials and methods}

\section{Sample collection and physicochemical measurements}

Considering nitrogen residues and ammonia accumulation in subtropical aquaculture ponds of China are most serious in autumn (from late August to late November), water samples of Tilapia nilotica culture ponds were collected from Yangjiang (YJ, 22.9 ${ }^{\circ} \mathrm{N}$, $112.7^{\circ} \mathrm{E}$, collected on September 28,2015$)$, Longchun (LC, $24.1^{\circ} \mathrm{N}, 115.2^{\circ} \mathrm{E}$, collected on October 8, 2015) and Qingyuan (QY, 23.9 ${ }^{\circ} \mathrm{N}, 113.9^{\circ} \mathrm{E}$, collected on September 22, 2015) in South China (Fig. 1). Three ponds in each area were randomly chosen and three surface water samples were collected from three different positions in each pond. 
Pond size (PS) and pond depth (PD) were surveyed by pond workmen. Water temperature (WT), dissolved oxygen (DO), oxidation reduction potential (ORP) and $\mathrm{pH}$ were measured in situ using a digital multi-meter (WTW, Weilheim, Germany). Ammonia nitrogen $\left(\mathrm{NH}_{4}{ }^{+}-\mathrm{N}\right)$ contents were measured using the Nash reagent photometry method, and nitrite $\left(\mathrm{NO}_{2}^{-}-\mathrm{N}\right)$ and nitrate $\left(\mathrm{NO}_{3}{ }^{-}-\mathrm{N}\right)$ contents were determined using n-(1-naphthyl)-ethylenediamine dihydrochloride spectrophotometric method and zinc/chromium (II) reduction method, respectively (Hepher et al., 1989; Huang, 2000). Chemical oxygen demand (COD) contents were measured using the $\mathrm{K}_{2} \mathrm{Cr}_{2} \mathrm{O}_{7}$ standard method (Barker et al., 1999; Huang, 2000). Total phosphorus (TP) and total nitrogen (TN) contents were measured using the molybdenum blue colorimetry and the Kjeldahl method, respectively (Huang, 2000).

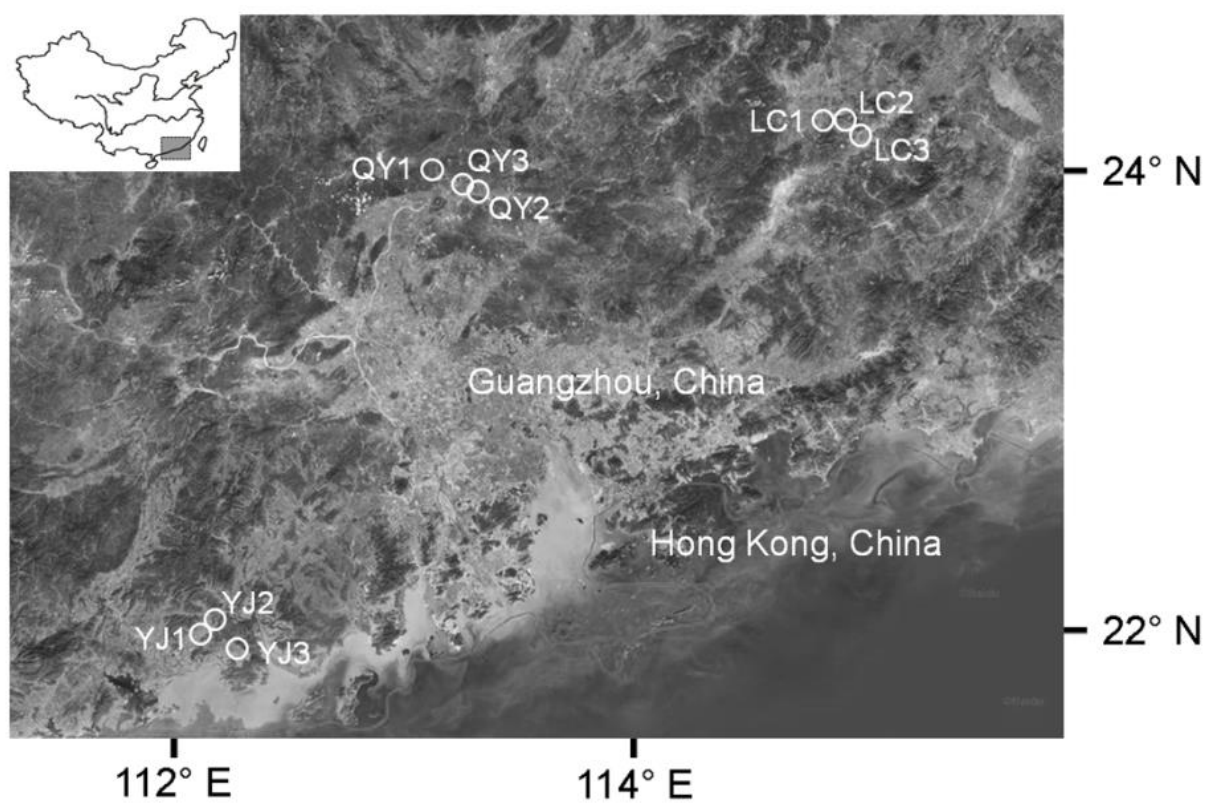

Figure 1. Distribution of sampled ponds. YJ, LC, and QY indicate the sampled ponds in Yangjiang $\left(22.9^{\circ} \mathrm{N}, 112.7^{\circ} \mathrm{E}\right)$, Longchun $\left(24.1^{\circ} \mathrm{N}, 115.2^{\circ} \mathrm{E}\right)$, and Qingyuan $\left(23.9^{\circ} \mathrm{N}, 113.9^{\circ} \mathrm{E}\right)$, respectively

\section{DNA extraction and sequencing}

Each $500 \mathrm{ml}$ water sample was filtered using glass-fiber GF/C filters with 0.45 and $0.22 \mu \mathrm{m}$ pore sizes. The filters were mixed and maintained at $-20{ }^{\circ} \mathrm{C}$ for DNA extraction. Microbial DNA was extracted according to the methods of Fang et al. (Fang et al., 2015) and purified using a Universal DNA Purification Kit (Tiangen Biotech, Beijing, China). DNA concentration and quality were checked using a NanoDrop spectrophotometer.

The V4-V5 hypervariable region of 16S rDNA was amplified and sequenced using the MiSeq sequencing platform, as described previously (Ni et al., 2017; Huang et al., 2018). The sequences were processed using the QIIME Pipeline with default parameters (Caporaso et al., 2010). Chimeric sequences were identified and removed using the Uchime algorithm before further analysis (Edgar et al., 2011). All samples were randomly re-sampled to obtain the same number of sequences. The high-quality sequences were clustered into operational taxonomic units (OTUs) at a 97\% identity 
using UPARSE (Edgar et al., 2013). Taxonomic assignments of each OTU were determined using the RDP classifier (Wang et al., 2007). Functional profiles of the microbiota were predicted using PICRUSt (Langille et al., 2013).

The sequences were deposited in the SRA database under accession number SRP095073.

\section{Real-time PCR conditions}

Relative levels of the bacterial $16 \mathrm{~S}$ rRNA and $\operatorname{nar} G$ genes were quantified using the primer pair w49dir (5' - CGGTCCAGACTCCTACGGG - 3') and w34rev (5' TTACCGCGGCTGCTGGCAC - 3') (Christman et al., 2011) and the primer pair narG328F (5' - GACAAACTTCGCAGCGG - 3') and narG497R (5' TCACCCAGGACGCTGTTC - 3') (Reyna et al., 2010), respectively. Each 25- $\mu$ l realtime PCR reaction mixture consisted of $1 \times$ FastQuant RT Mixture (TIANGEN, Beijing, China) containing $200 \mathrm{nM}$ each primer and $20 \mathrm{ng}$ of DNA. Blank controls were designed using sterile water, instead of DNA. The reactions were performed by incubation for $10 \mathrm{~min}$ at $95{ }^{\circ} \mathrm{C}$, following by $30 \mathrm{~s}$ at $95{ }^{\circ} \mathrm{C}, 30 \mathrm{~s}$ at $55^{\circ} \mathrm{C}$ and $45 \mathrm{~s}$ at 72 ${ }^{\circ} \mathrm{C}$ for 35 cycles. Each sample was analyzed in triplicate. Real-time PCR amplification was performed using an ABI PRISM 7000 Sequence Detection System (Applied Biosystems, Waltham, USA) and the data were analyzed using ABI PRISM 7000 Sequence Detection software v1.0 (Applied Biosystems, Waltham, USA).

\section{Data analysis}

Constrained correspondence analysis (CCA) with Monte Carlo permutation test and non-parametric multivariate analysis of variance (MANOVA) were conducted using the $R$ vegan package (Anderson, 2001; Dixon, 2003). Significances of correlations between environmental factors and OTUs were detected using the $\mathrm{R}$ software with basic packages. $P$-values $\leq 0.05$ were considered statistically significant.

\section{Results and Discussion}

\section{Composition of pond microbiota}

After removing low quality sequences, 569160 sequences were obtained for the 27 samples. After random re-sampling, each sample retained 8898 sequences. Similar with a previous report of freshwater (Nold and Zwart, 1998), Proteobacteria, Cyanobacteria, Bacteroidetes, Planctomycetes and Verrucomicrobia were the dominant phyla. However, the relative proportions of the dominant phyla differed among the ponds (Fig. 2).

A total of 59380 OTUs, including 614 dominant OTUs (relative abundances in at least one sample $>0.1 \%$ ) were detected. Sixty-one dominant OTUs appeared in more than half of the samples as dominant OTUs. Most dominant OTUs were assigned to taxa that exhibit nitrogen metabolism according to previous studies. Caldilinea aerophila DSM 14535 contains atypical NosZ (Sanford et al., 2012). Hydrogenophaga with nitrate reduction ability has been isolated from reed pond water (Du et al., 2015). Planctomycesis an anammox bacteria that is widespread in multiple habitats (Wang et al., 2012; Van Teeseling et al., 2015). Acinetobacter johnsonii has the potential to remove $\mathrm{NH}_{4}{ }^{+}-\mathrm{N}$ (Straganz et al., 2003; Straganz and Nidetzky, 2005). Cetobacterium somerae isolated from the intestinal tracts of freshwater fish exhibits esculin hydrolysis and nitrate reduction activity (Tsuchiya et al., 2008). 




Figure 2. Dominant prokaryotic phyla in South China ponds. YJ, LC, and QY indicate the sampled ponds in Yangjiang $\left(22.9^{\circ} \mathrm{N}, 112.7^{\circ} \mathrm{E}\right)$, Longchun $\left(24.1^{\circ} \mathrm{N}, 115.2^{\circ} \mathrm{E}\right)$, and Qingyuan $\left(23.9^{\circ} \mathrm{N}, 113.9^{\circ} \mathrm{E}\right)$, respectively. The lateral axis shows the sample names, and the vertical axis shows the relative abundance of each prokaryotic phylum in the pond microbiota

\section{Spatial differentiation of pond microbiota}

Microbiota from the same pond tended to cluster together based on principal coordinate analysis (PCoA).The microbiota exhibited significant differences among ponds (MANOVA, $p<0.01$ ), with the exceptions of the microbiota in LC3 and QY1 or QY3, and the microbiota in QY2 and LC2. In addition, regional trends also emerged (Fig. 3A), i.e., microbiota were significantly differentiated with respect to sampling region. The microbiota exhibited significant differentiation between YJ and LC (MANOVA, $F=3.0808, p=0.005$ ), between YJ and QY (MANOVA, $F=3.5724, p=$ 0.005 ), and between LC and QY (MANOVA, $F=1.9873, p=0.020$ ).

A total of 196 dominant OTUs were detected, with differences in composition across sampling areas. However, only a tiny fraction was confined to a single pond or a single sampling area, or was absent from a single sampling area. Most OTUs exhibited differences in relative abundance among sampling areas.

\section{Correlations among pond microbiota and environmental factors}

Based on a CCA, environmental factors significantly influenced the structure of pond microbiota (Monte Carlo permutation test, Pseudo- $F=1.287, p=0.001$ ). Specifically, $\mathrm{PD}, \mathrm{WT}, \mathrm{PS}, \mathrm{COD}, \mathrm{TP}, \mathrm{NO}_{3}-\mathrm{N}$ and $\mathrm{pH}$ significantly influenced the structure of pond microbiota (Fig. 3B). Different environmental factors were significantly correlated with OTUs from different phylogenetic clades (Table 1). These results implied there was no dispersal restriction for most of the pond microorganisms. They were cosmopolitan, and spatial patterns of diversity were driven by environmental heterogeneity, consistent with the claim that "everything is everywhere, the environment selects" (Fenchel and Finlay, 2004). The relative abundance of the anammox bacteria Planctomyces was significantly correlated with the concentrations of both COD and TP (Wang et al., 2012; Van 
Teeseling et al., 2015). Therefore, it is possible to indirectly regulate the rate of anammox by changing the concentrations of COD or TP, thereby regulating the relative abundance of Planctomyces.
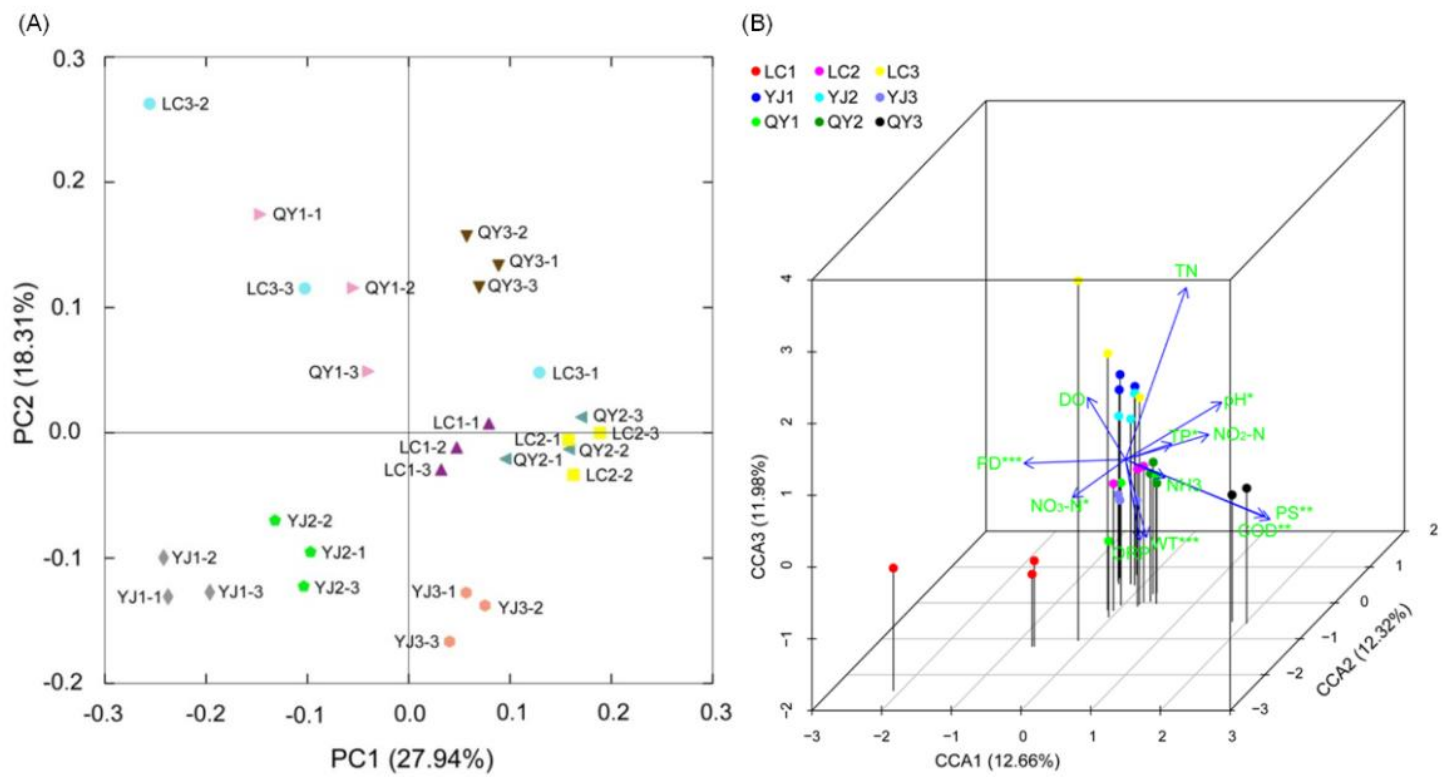

Figure 3. Principal coordinate analysis $(A)$ and constrained correspondence analysis $(B)$ profiles showing the correlation between pond microbial OTUs and environmental factors. * indicates the p-value was less than 0.05 . ** indicates the p-value was less than 0.01 . *** indicates the p-value was less than 0.001. YJ, LC, and QY indicated the sampled ponds in Yangjiang $\left(22.9^{\circ} \mathrm{N}, 112.7^{\circ} \mathrm{E}\right)$, Longchun $\left(24.1^{\circ} \mathrm{N}, 115.2^{\circ} \mathrm{E}\right)$, and Qingyuan $\left(23.9^{\circ} \mathrm{N}, 113.9^{\circ} \mathrm{E}\right)$, respectively. TN: total nitrogen; TP: total phosphorus; COD: chemical oxygen demand; ORP: oxidation reduction potential; DO: dissolved oxygen; WT: water temperature; PS: pond size; PD: pond depth

\section{Potential metabolic capability of pond microbiota}

Most of the nitrogen metabolic genes were detected from the predictive metagenomes. In addition, the genes in the pathways from nitrate to ammonia were obviously excess than those from nitrate to nitrogen or from ammonia to nitrogen (Fig. $4 a$ ). This implied that nitrogen probably accumulated in pond by ammonia.

To verify the reliability of the predicted functional profiles of the microbiota, narG was quantified by real-time PCR using LC samples. Three independent real-time PCRs were conducted for the relative quantification of gene abundance in LC1-2, LC3-1, and LC3-2, LC1-3, LC2-3, and LC3-3, and LC1-1, LC2-1 and LC2-2. According to the threshold cycle $\left(C_{t}\right)$ values, the abundance of the $16 \mathrm{~S}$ rRNA gene was $333.64 \pm 218.66$ (mean $\pm \mathrm{SD}$, range 49.75-654.08) times great than that of $n a r G$ in the microbiota. Although the relative abundance of $\operatorname{nar} G$ based on PICRUSt prediction and real-time PCR results were not identical, there were similar trends in their relative proportions between samples (Table 2). The difference between the PICRUSt prediction and realtime PCR results might reflect the insufficiency of the database used for the PICRUSt prediction or real-time PCR primers that did not cover the entire narG gene. These results implied that PICRUSt prediction is suitable to determine the relative proportions of functional genes in different microbiota. 
Table 1. Correlations between environmental factors and their significant correlated OTUs. TP: total phosphorus; COD: chemical oxygen demand; DO: dissolved oxygen; WT: water temperature

\begin{tabular}{|c|c|c|c|}
\hline $\begin{array}{c}\text { Environmental } \\
\text { factors }\end{array}$ & $\begin{array}{c}\text { Phylogenetic clade of the } \\
\text { OTUs }\end{array}$ & Regression equation* & $R^{2}$ \\
\hline \multirow[t]{7}{*}{$\mathrm{COD}$} & Cerasicoccaceae & $y=3 \times 10^{-7} x^{2}-6 \times 10^{-5} x+0.0042$ & 0.507 \\
\hline & Sphingobacteriales & $y=5 \times 10^{-8} x^{2}-1 \times 10^{-5} x+0.0005$ & 0.410 \\
\hline & Planctomyces & $y=4 \times 10^{-7} x^{2}-0.0001 x+0.0134$ & 0.361 \\
\hline & Pirellulaceae & $y=-2 \times 10^{-7} x^{2}+0.0001 x-0.0071$ & 0.347 \\
\hline & ACK-M1 & $y=2 \times 10^{-6} x^{2}-0.0002 x+0.0107$ & 0.372 \\
\hline & LD19 & $y=2 \times 10^{-6} x^{2}-0.0004 x+0.0267$ & 0.412 \\
\hline & Pirellulaceae & $y=5 \times 10^{-8} x^{2}-9 \times 10^{-6} x+0.0004$ & 0.421 \\
\hline \multirow[t]{8}{*}{ WT } & Chitinophagaceae & $y=9 \times 10^{-5} x^{2}-0.0058 x+0.0958$ & 0.849 \\
\hline & Saprospiraceae & $y=-0.001 x+0.0347$ & 0.594 \\
\hline & Chitinophagaceae & $y=4 \times 10^{-5} x^{2}-0.0027 x+0.0476$ & 0.399 \\
\hline & LD19 & $y=0.0018 x^{2}-0.105 x+1.545$ & 0.468 \\
\hline & Pseudomonas stutzeri & $y=2 \times 10^{-5} x^{2}-0.0013 x+0.0191$ & 0.378 \\
\hline & Sphingobacteriales & $y=0.0002 x^{2}-0.0103 x+0.1624$ & 0.411 \\
\hline & WCHB $1-5$ & $y=0.0001 x^{2}-0.0089 x+0.1405$ & 0.431 \\
\hline & Polynucleobacter & $y=0.0002 x^{2}-0.013 x+0.2036$ & 0.571 \\
\hline $\mathrm{DO}$ & Chitinophagaceae & $y=3 \times 10^{-5} x^{2}-0.0003 x+0.0016$ & 0.37 \\
\hline \multirow[t]{5}{*}{$\mathrm{pH}$} & Stramenopiles & $y=0.0014 x^{2}-0.0261 x+0.1174$ & 0.342 \\
\hline & MWH-UniP1 & $y=2 \times 10^{-9} x^{6.7374}$ & 0.402 \\
\hline & Sinobacteracea & $y=0.0002 x^{2}-0.0034 x+0.0152$ & 0.328 \\
\hline & Polynucleobacter & $y=0.0007 x^{2}-0.0124 x+0.0574$ & 0.367 \\
\hline & Chitinophagaceae & $y=0.0012 x^{2}-0.0184 x+0.0729$ & 0.393 \\
\hline \multirow{6}{*}{$\mathrm{NH}_{4}{ }^{+}-\mathrm{N}$} & $\mathrm{C} 111$ & $y=0.0199 x+9 \times 10^{-5}$ & 0.431 \\
\hline & ACK-M1 & $y=0.0227 x^{2}-0.0024 x+0.0013$ & 0.392 \\
\hline & Solirubrobacterales & $y=0.0023 x+3 \times 10^{-5}$ & 0.372 \\
\hline & MWH-UniP1 & $y=-0.1101 x^{2}-0.0562 x+0.0005$ & 0.420 \\
\hline & Sediminibacterium & $y=-0.004 \ln (x)-0.0039$ & 0.366 \\
\hline & Actinomycetales & $y=0.0169 x+0.0003$ & 0.366 \\
\hline \multirow[t]{8}{*}{$\mathrm{NO}_{2}^{-}-\mathrm{N}$} & Betaproteobacteria & $y=-0.026 x^{2}+0.017 x$ & 0.554 \\
\hline & Fluviicola & $y=0.004 x^{2}-0.002 x$ & 0.401 \\
\hline & $\begin{array}{c}\text { Candidatus } \\
\text { Xiphinematobacter }\end{array}$ & $y=-0.012 x^{2}+0.011 x-2 \times 10^{-5}$ & 0.445 \\
\hline & Polynucleobacter & $y=0.018 x^{2}-0.008 x+0.001$ & 0.347 \\
\hline & Chroococcales & $y=-0.445 x^{2}+0.286 x$ & 0.364 \\
\hline & Pirellulaceae & $y=-0.009 x^{2}+0.006 x$ & 0.517 \\
\hline & ACK-M1 & $y=-0.378 x^{2}+0.269 x-0.007$ & 0.518 \\
\hline & Phycisphaerales & $y=-0.045 x^{2}+0.032 x$ & 0.501 \\
\hline \multirow[t]{4}{*}{$\mathrm{NO}_{3}^{-}-\mathrm{N}$} & Chitinophagaceae & $y=-6 \ln (x)$ & 0.406 \\
\hline & Pseudomonas stutzeri & $y=0.001 x$ & 0.422 \\
\hline & WCHB1-50 & $y=-8 \ln (x)$ & 0.546 \\
\hline & Saprospiraceae & $y=-2 \ln (x)$ & 0.370 \\
\hline \multirow[t]{5}{*}{$\mathrm{TP}$} & SC3 & $y=0.068 x^{2}-0.022 x+0.001$ & 0.348 \\
\hline & Planctomyces & $y=0.188 x^{2}-0.058 x+0.005$ & 0.594 \\
\hline & Mycobacterium & $y=-0.106 x^{2}+0.044 x-0.001$ & 0.349 \\
\hline & Opitutus & $y=-3 \ln (x)$ & 0.335 \\
\hline & Oxalobacteraceae & $y=0.023 x^{2}-0.011 x+0.001$ & 0.373 \\
\hline
\end{tabular}

* Lowercases $\mathrm{x}$ and $\mathrm{y}$ indicate the concentrations or values of environmental factors, and the relative abundances of OTUs, respectively 
Although the abundances of many genes differed significantly between ponds, complementary patterns involving different genes that participate in the same metabolic pathway emerged. For example, nirB and nirD were significantly more abundant in the YJ ponds than in other ponds, while K01501, which participates in the same pathway, was significantly less abundant in YJ ponds. The gltB and gltD genes were significantly more abundant in the YJ ponds than in other ponds, while K00284 was significantly less abundant (Fig. 4b).

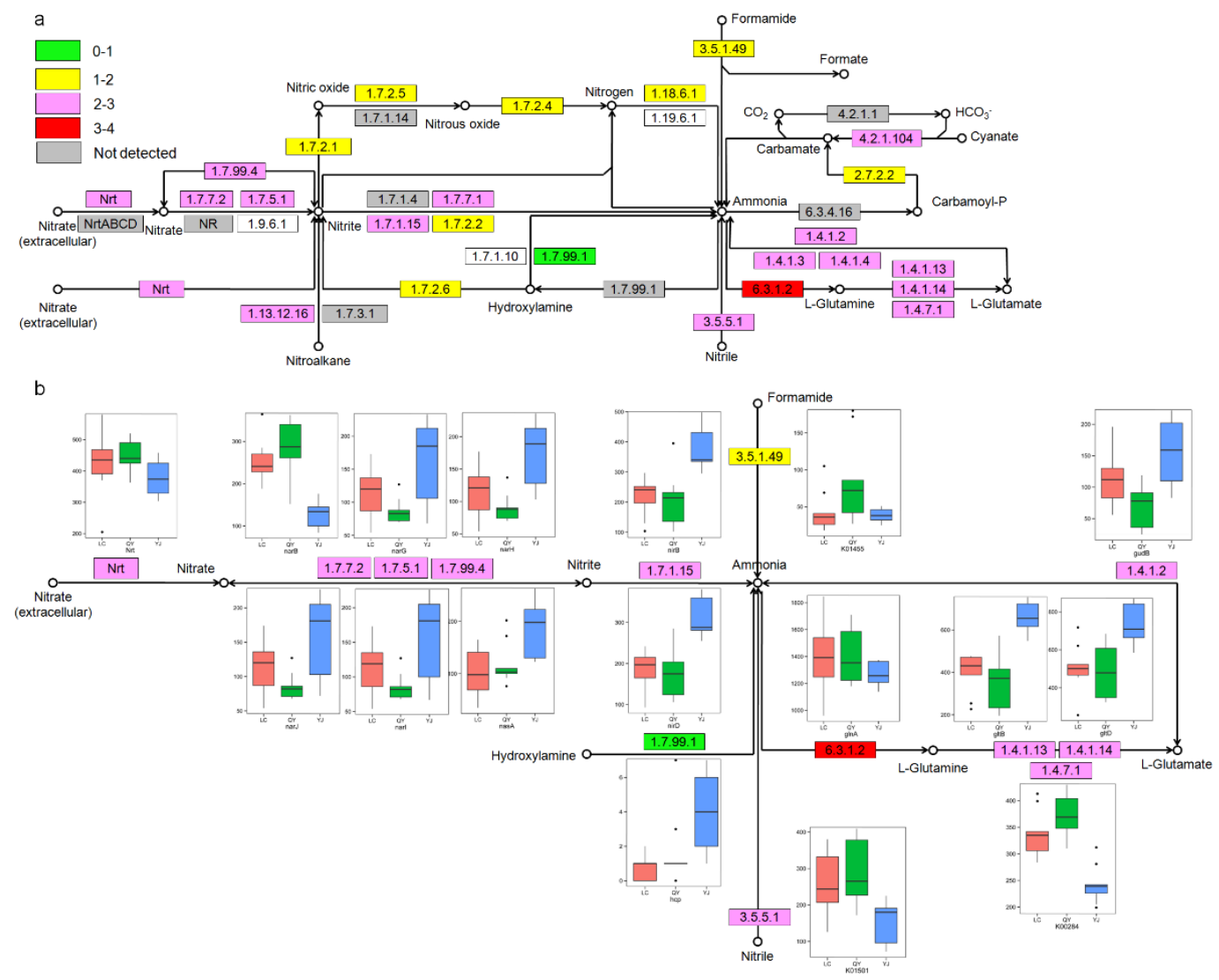

Figure 4. KEGG pathway analysis of nitrogen metabolism showing the abundances of relevant genes (a) and genes for the abundance differed significantly between ponds $(b)$. The abundances of relevant genes are logarithmic transformed. YJ, LC, and QY indicate the sampled ponds in Yangjiang $\left(22.9^{\circ} \mathrm{N}, 112.7^{\circ} \mathrm{E}\right)$, Longchun $\left(24.1^{\circ} \mathrm{N}, 115.2^{\circ} \mathrm{E}\right)$, and Qingyuan $\left(23.9^{\circ} \mathrm{N}, 113.9^{\circ} \mathrm{E}\right)$, respectively

Table 2. Relative abundance of narG gene in pond microbiota

\begin{tabular}{ccc}
\hline Relative abundance & PICRUSt predicted value & Real-time PCR value \\
\hline Abun(LC1-3)/Abun(LC3-3) & 0.3885 & 0.6199 \\
Abun(LC2-3)/Abun(LC3-3) & 1.2446 & 1.3755 \\
Abun(LC2-3)/Abun(LC1-3) & 3.2037 & 2.2191 \\
Abun(LC2-1)/Abun(LC2-2) & 0.8583 & 0.4024 \\
Abun(LC1-1)/Abun(LC2-2) & 0.7250 & 0.3536 \\
Abun(LC1-1)/Abun(LC2-1) & 0.8447 & 0.8786 \\
Abun(LC1-2)/Abun(LC3-2) & 0.9708 & 1.3883 \\
Abun(LC3-1)/Abun(LC3-2) & 0.5036 & 0.2360 \\
Abun(LC3-1)/Abun(LC1-2) & 0.5188 & 0.0762 \\
\hline
\end{tabular}


In intensive aquaculture pond systems, fish is cultured at densities up to $90 \mathrm{~kg}$ of living biomass $\mathrm{m}^{-3}$ (Conte, 2004). However, in these feed-driven pond systems, only 20-30\% of the nitrogen input is converted into harvestable products (Azim et al., 2003; De Schryver and Verstraete, 2009). Ammonium is one of the end products of protein metabolism in pond water. Using the ${ }^{15} \mathrm{~N}$ labeled ammonium, Kawai and Sugiyama (1979) proved that ammonium nitrogen metabolized was incorporated into the organisms of the primary trophic level and only a small amount of the ammonium nitrogen was incorporated into the organisms of the higher trophic level, i.e. zooplankton and fish in the model system of a goldfish culturing pond. They also found that ammonium nitrogen in the water was oxidized to nitrate via nitrites and a considerable part of the nitrite nitrogen was transformed to gaseous nitrogen in the process of bacterial denitrification. In addition, it is well documented that bacteria in the water and sediments remove these nitrogen products by nitrification and denitrification ( $\mathrm{Lu}$ et al., 2015) and a lot of nitrogen metabolic bacteria were isolated from pond water and sediment (Fu et al., 2012; Wang et al., 2012; Van Teeseling et al., 2015; Du et al., 2015). However, the compositions of pond water microbiota and their potential nitrogen metabolic genes were still rarely studied. In the present study, we showed that there were diverse nitrogen metabolic bacteria inhabiting in the subtropical aquaculture pond water in China and they exhibited complementary nitrogen metabolic potentiality (Fig. 4).

In conclusion, the microbiota inhabiting subtropical aquaculture ponds included various functional microorganisms. Their structures were significantly influenced by WT, PD, COD, PS, pH, TP and $\mathrm{NO}_{3}^{-}-\mathrm{N}$. Most genes related to nitrogen metabolism were detected from the predictive pond metagenomes, and complementary patterns emerged where by different genes in the same metabolic pathway were detected in different ponds.

Acknowledgements. We greatly appreciate Fei Liu, Xunan Yang and Ou Luo from the Guangdong Institute of Microbiology for their help in collecting samples. This research was supported by the Special Fund for Agro-scientific Research in the Public Interest (201503108); the Nature Science Foundation of China (grant number 31500417, 51678163); GDAS' Special Project of Science and Technology Development (2017GDASCX-0401, 2016GDASRC-0208, 2018GDASCX-0102), and Science and Technology Project of Guangzhou (201707020021).

\section{REFERENCES}

[1] Anderson, M. J. (2001): A new method for non-parametric multivariate analysis of variance. - Austral Ecology 26(1): 32-46.

[2] Azim, M. E., Verdegem, M. C. J., Singh, M. (2003): The effects of periphyton substrate and fish stocking density on water quality, phytoplankton, periphyton and fish growth. Aquaculture Research 24(9): 685-695.

[3] Barker, D. J., Mannucchi, G. A., Salvi, S. M. L., Stuckey, D. C. (1999): Characterisation of soluble residual chemical oxygen demand (COD) in anaerobic wastewater treatment effluents. - Water Research 33(11): 2499-2510.

[4] Camargo, J. A., Alonso, A., Salamanca, A. (2005): Nitrate toxicity to aquatic animals: a review with new data for freshwater invertebrates. - Chemosphere 58(9): 1255-1267.

[5] Caporaso, J. G., Kuczynski, J., Stombaugh, J. (2010): QIIME allows analysis of highthroughput community sequencing data. - Nature Methods 7(5): 335-336.

[6] Christman, G. D., Cottrell, M. T., Popp, B. N. (2011): Abundance, diversity, and activity of ammonia-oxidizing prokaryotes in the coastal arctic ocean in summer and winter. - 
Applied and Environmental Microbiology 77(6): 2026-2034.

[7] Conte, F. S. (2004): Stress and the welfare of cultured fish. - Applied Animal Behaviour Science 86(3-4): 205-223.

[8] Crab, R., Avnimelech, Y., Defoirdt, T. (2007): Nitrogen removal techniques in aquaculture for a sustainable production. - Aquaculture 270(1-4): 1-14.

[9] De Schryver, P., Verstrete, W. (2009): Nitrogen removal from aquaculture pond water by heterotrophic nitrogen assimilation in lab-scale sequencing batch reactors. - Bioresource Technology 100: 1162-1167.

[10] Dixon, P. (2003): VEGAN, a package of R functions for community ecology. - Journal of Vegetation Science 14(6): 927-930.

[11] Du, J., Yang, J., Singh, H. (2015): Hyderogenophagaluteola sp. nov. isolated from reed pond water. - Antonie van Leeuwenhoek 108: 695-701.

[12] Edgar, R. C., Haas, B. J., Clemente, J. C. (2011): UCHIME improves sensitivity and speed of chimera detection. - Bioinformatics 27(16): 2194-2200.

[13] Edgar, R. C. (2013): UPARSE: highly accurate OTU sequences from microbial amplicon reads. - Nature Methods 10(10): 996-998.

[14] Fang, Y., Xu, M., Chen, X. (2015): Modified pretreatment method for total microbial DNA extraction from contaminated river sediment. - Frontiers of Environmental Science \& Engineering 9(3): 444-452.

[15] FAO. (2014): The state of world fisheries and aquaculture 2014. - Food and Agricultural Organization of the United Nations, New York.

[16] Fenchel, T., Finlay, B. J. (2004): The ubiquity of small species: patterns of local and global diversity. - Bioscience 54(8): 777-784.

[17] Fu, L., Sun, J., Deng, B. (2012): Analysis of cultivable heterotrophic bacteria involved in nitrogen cycle in grass carp (Ctenopharyngodon idellus) pond. - Journal of Fisheries of China 36(10): 1572-1578.

[18] Gutierrez-Wing, M. T., Malone, R. F. (2006): Biological filters in aquaculture: trends and research directions for freshwater and marine applications. - Aquacultural Engineering 34(3): 163-171.

[19] Hepher, M. J., Alexander, R. H., Dixon, J. (1989). Zinc/chromium (II) reduction for nitrate determination in agriculture materials by colorimetry or ion-selective electrode. Journal of the Science of Food and Agriculture 49(3): 379-383.

[20] Huang, X. F. (2000): Survey, observation and analysis of lake ecology. - China Standard Press, Beijing.

[21] Huang, R., Li, T., Ni, J. (2018): Different sex-based responses of gut microbiota during the development of hepatocellular carcinoma in liver-specific Tsc1-knockout mice. Frontiers in Microbiology 9: 1008.

[22] Kawai, A., Sugiyama, M. (1979): Microbiological studies on the nitrogen cycle in aquatic environmnets-V. Nitrogen metabolism in the goldfish culturing pond. - Bulletin of the Japanese Society of Scientific Fisheries 45(1): 61-65.

[23] Langille, M. G. I., Zaneveld, J., Caporaso, J. G. (2013): Predictive functional profiling of microbial communities using 16S rRNA marker gene sequences. - Nature Biotechnology 31: 814-821.

[24] Liu, J., Diamond, J. (2005): China's environment in a globalizing world. - Nature 435: $1179-1186$.

[25] Lu, S., Liao, M., Xie, C. (2015): Seasonal dynamics of ammonia-oxidizing microorganisms in freshwater aquaculture ponds. - Annals of Microbiology 65(2): 651657.

[26] Mook, W. T., Chakrabarti, M. H., Aroua, M. K. (2012): Removal of total ammonia nitrogen (TAN), nitrate and total organic carbon (TOC) from aquaculture wastewater using electrochemical technology: A review. - Desalination 285: 1-13.

[27] Naylor, R. L., Goldburg, R. J., Primaver, J. H. (2000): Effect of aquaculture on world fish supplies. - Nature 405: 1017-1024. 
[28] Ni, J., Li, X., He, Z., Xu, M. (2017): A novel method to determine the minimum number of sequences required for reliable microbial community analysis. - Journal of Microbiological Methods 139: 196-201.

[29] Nold, S. C., Zwart, G. (1998): Patterns and governing forces in aquatic microbial communities. - Aquatic Ecology 32(1): 17-35.

[30] Piedrahita, R. H. (2003): Reducing the potential environmental impact of tank aquaculture effluents through intensification and recirculation. - Aquaculture 226(1-4): $35-44$.

[31] Reyna, L., Wunderlin, D. A., Genti-Raimondi, S. (2010): Identification and quantification of a novel nitrate-reducing community in sediments of Suquía River basin along a nitrate gradient. - Environmental Pollution 158(5): 1608-1614.

[32] Sanford, R. A., Wagner, D. D., Wu, Q. (2012): Unexpected nondenitrifier nitrous oxide reductasegene diversity and abundance in soils. - Proceedings of the National Academy of Sciences of the United States of America 109(48): 19709-19714.

[33] Shen, L., Wu, H., Gao, Z. (2016): Evidence for anaerobic ammonium oxidation process in freshwater sediments of aquaculture ponds. - Environmental Science and Pollution Research International 23(2): 1344-1352.

[34] Straganz, G. D., Glieder, A., Brecker, L., Ribbons, D. W., Steiner, W. (2003): Acetylacetone-cleaving enzyme Dke1: a novel C-C-bond-cleaving enzyme from Acinetobacter johnsonii. - BioChemical Journal 369(Pt 3): 573-581.

[35] Straganz, G. D., Nidetzky, B. (2005): Reaction coordinate analysis for beta-diketone cleavage by the non-heme Fe2+-dependent dioxygenase Dkel. - Journal of American Chemical Society 127(35): 12306-12314.

[36] Tsuchiya, C., Sakata, T., Sugita, H. (2008): Novel ecological niche of Cetobacteriumsomerae, an anaerobic bacterium in the intestinal tracts of freshwater fish. - Letters in Applied Microbiology 46(1): 43-48.

[37] Van Teeseling, M. C . F., Mesman, R. J., Kuru, E. (2015): Anammox planctomycetes have a peptidoglycan cell wall. - Nature Communications 6: 6878.

[38] Wang, Q., Garrity, G. M., Tiedje, J. M. (2007): Naïve Bayesian classifier for rapid assignment of rRNA sequences into the new bacterial taxonomy. - Applied and Environmental Microbiology 73(16): 5261-5267.

[39] Wang, Y., Sheng, H., He, Y. (2012): Comparison of the levels of bacterial diversity in freshwater, intertidal wetland, and marine sediments by using millions of Illumina tags. Applied and Environmental Microbiology 78(23): 8264-8271. 